\title{
PROGRESS IN AMS TARGET PRODUCTION OF SUB-MILLIGRAM SAMPLES AT THE NERC RADIOCARBON LABORATORY
}

\author{
Tanya Ertunç $c^{1,2} \bullet$ Sheng $\mathrm{Xu}^{3} \bullet$ Charlotte L Bryant ${ }^{1} \bullet$ Colin Maden $^{3} \bullet$ Callum Murray ${ }^{1} \bullet$ \\ Margaret Currie ${ }^{1} \bullet$ Stewart P H T Freeman ${ }^{3}$
}

\begin{abstract}
Recent progress in graphite target production for sub-milligram environmental samples in our facility is presented. We describe an optimized hydrolysis procedure now routinely used for the preparation of $\mathrm{CO}_{2}$ from inorganic samples, a new high-vacuum line dedicated to small sample processing (combining sample distillation and graphitization units), as well as a modified graphitization procedure. Although measurements of graphite targets as small as $35 \mu \mathrm{g} C$ have been achieved, system background and measurement uncertainties increase significantly below $150 \mu \mathrm{g} \mathrm{C}$. As target lifetime can become critically short for targets $<150 \mu \mathrm{g} \mathrm{C}$, the facility currently only processes inorganic samples down to $150 \mu \mathrm{g} \mathrm{C}$. All radiocarbon measurements are made at the Scottish Universities Environmental Research Centre (SUERC) accelerator mass spectrometry (AMS) facility. Sample processing and analysis are labor-intensive, taking approximately 3 times longer than samples $\geq 500 \mu \mathrm{g} \mathrm{C}$. The technical details of the new system, graphitization yield, fractionation introduced during the process, and the system blank are discussed in detail.
\end{abstract}

\section{INTRODUCTION}

The Natural Environment Research Council (NERC) Radiocarbon Laboratory deals with a large variety of environmental samples such as sediment, soil, peat, wood, pollen, shell, coral, foraminifera, dissolved and particulate organic and inorganic carbon, methane, as well as hydrocarbon fractions. Since 2004, all of the facility's accelerator mass spectrometer (AMS) radiocarbon analyses have been carried out on the new National Electrostatics Corporation (NEC) 5MV AMS at the Scottish Universities Environmental Research Centre (SUERC) (Freeman et al. 2004).

Using routine methods, graphite targets down to a size of $500 \mu \mathrm{g} \mathrm{C}$ can be successfully produced and analyzed on the new NEC AMS. Targets $<500 \mu \mathrm{g} C$ were found to perform inconsistently in terms of durability during sputtering in the ion source, and with variable background levels. The former is due to the properties of the iron catalyst routinely used and the latter to contamination introduced during sample preparation. To accommodate the increasing need for the analysis of submilligram samples by AMS, routine methods had either to be refined to achieve acceptable procedural blanks, or new methods and equipment had to be developed to expand the facility's capability to process and measure such samples.

A purpose-built high-vacuum unit was developed to extract, trap, cryogenically distill, and graphitize carbon from inorganic and organic samples. Before using the new system for sample processing, system and processing backgrounds have to be quantified and AMS parameters have to be defined for reliable measurements of targets $<500 \mu \mathrm{g} \mathrm{C}$. The purpose-built vacuum line and the hydrolysis procedure to obtain $\mathrm{CO}_{2}$ from inorganic samples will be described. Background levels, the modified graphitization procedure, the optimized graphitization yield, and the fractionation introduced during target production on the purpose-built line will also be discussed. Sample sizedependent fractionation has been observed at other facilities (Hofmann et al. 1984; Nadeau et al. 1987; McNichol et al. 1992; van der Borg et al. 1997; Pearson et al. 1998; Hua et al. 2004), but does not necessarily reflect the characteristics of our facilities, as a variety of mechanisms, including graphitization and AMS measurement, may contribute to the isotopic fractionation (Pearson et al.

${ }^{1}$ Natural Environment Research Council (NERC) Radiocarbon Laboratory, Scottish Enterprise Technology Park, Rankine Avenue, East Kilbride G75 0QF, United Kingdom.

${ }^{2}$ Corresponding author. Email: T.Ertunc@nercrcl.gla.ac.uk.

${ }^{3}$ Scottish Universities Environmental Research Centre (SUERC), Scottish Enterprise Technology Park, East Kilbride G75 0QF, United Kingdom. 
1998). The effect of the graphitization is reported and studies to elucidate the influence of AMS measurement are currently underway and will be published in the future. In addition to its use for development work, the new distillation and graphitization unit is now routinely used for preparation of sub-milligram targets of inorganic carbon.

\section{METHODS}

\section{High Vacuum Line for Small Sample Processing}

As in most target preparation laboratories and AMS facilities, the measured background of our samples is, apart from residual in situ contamination, mainly introduced during sample preparation. The SUERC AMS machine background is $<0.03 \mathrm{pMC}$, based on the measurement of ultra pure graphite powder (Freeman et al. 2004), whereas our process blank of inorganic samples $>500 \mu \mathrm{g} \mathrm{C}$ is $0.2 \pm 0.1 \mathrm{pMC}$. As the background becomes increasingly significant with decreasing sample size, we designed a purpose-built vacuum line aimed to reduce most of the known contamination sources (Vogel et al. 1987; Kirner et al. 1995; Vandeputte et al. 1998) during $\mathrm{CO}_{2}$ handling and graphitization. The functional units of $\mathrm{CO}_{2}$ distillation, volume measurement, and graphitization are combined in one unit, minimizing gas handling and thus reducing the possibility of contamination or sample fractionation (Vogel et al. 1987). If necessary, purified $\mathrm{CO}_{2}$ can still be sealed for longterm storage. A similar but more complex approach is also applied in other laboratories handling extremely small samples (Pohlman et al. 2000).

Figure 1 shows a schematic overview of the vacuum line. To maintain a consistently high vacuum, the overall size of the new system was kept small in comparison to our normal vacuum lines. It combines 3 different sections: 1) a manifold allowing evacuation of 4 reaction vessels during sample processing; 2) a $\mathrm{CO}_{2}$-distillation section and calibrated standard volume (STV) for volumes between 0.015 and $0.5 \mathrm{~mL}$; and 3) 4 graphite reaction vessels. Dry pumps have been used to avoid any carbon contamination from oil pumps; to achieve a consistent minimum vacuum of $2 \mathrm{E}-5$ mbar, the system is connected to a turbomolecular pump backed by a scroll pump to evacuate the system from atmospheric pressure. The line is made of electropolished stainless steel. The metal tubing can be heated to $100{ }^{\circ} \mathrm{C}$ to achieve a better vacuum and to maximize removal of contaminants. The only glass components are the calibrated standard volume, the water trap (Pyrex ${ }^{\mathrm{TM}}$, custom built), and the quartz tubes used for graphitization. All tube connectors, tube fittings, O-ring-sealed Cajon UltraTorr fittings, flexible tubing for the pump connection, and valves were purchased from Swagelok ${ }^{\circledR}$. The vacuum measurement in the system is accomplished using a Pirani gauge and a wide range gauge; the pressure in the graphitization vessels and the standard volume is measured by 5 strain gauges (all BOC Edwards, West Sussex, UK). The gauges are connected to electronic control and display units. The signals from the electronic units are displayed on a portable computer and processed by a purpose-written program, which also allows the graphitization yield to be calculated. The Appendix contains a detailed list of the components used.

\section{Graphitization of Samples $<500 \mu g$ C}

\section{Improvement of Reaction Vessels}

The graphitization system is based on the Fe/Zn method (Slota et al. 1987; Hua et al. 2004; Mueller and Muzikar 2002). As the furnaces $\left(\right.$ Carbolite $\left.^{\circledR}\right)$ on our routine graphitization vessels were rather heavy, the $\mathrm{Zn}$ - and Fe-reaction vessels were initially connected using an $\mathrm{H}$-shaped design (Figure 2, design A) with a quartz glass bridge and Cajon fittings. The total volume of the reaction vessels was $7.5 \mathrm{~mL}$. To keep the transducer heads at room temperature and reduce electronic background noise, 


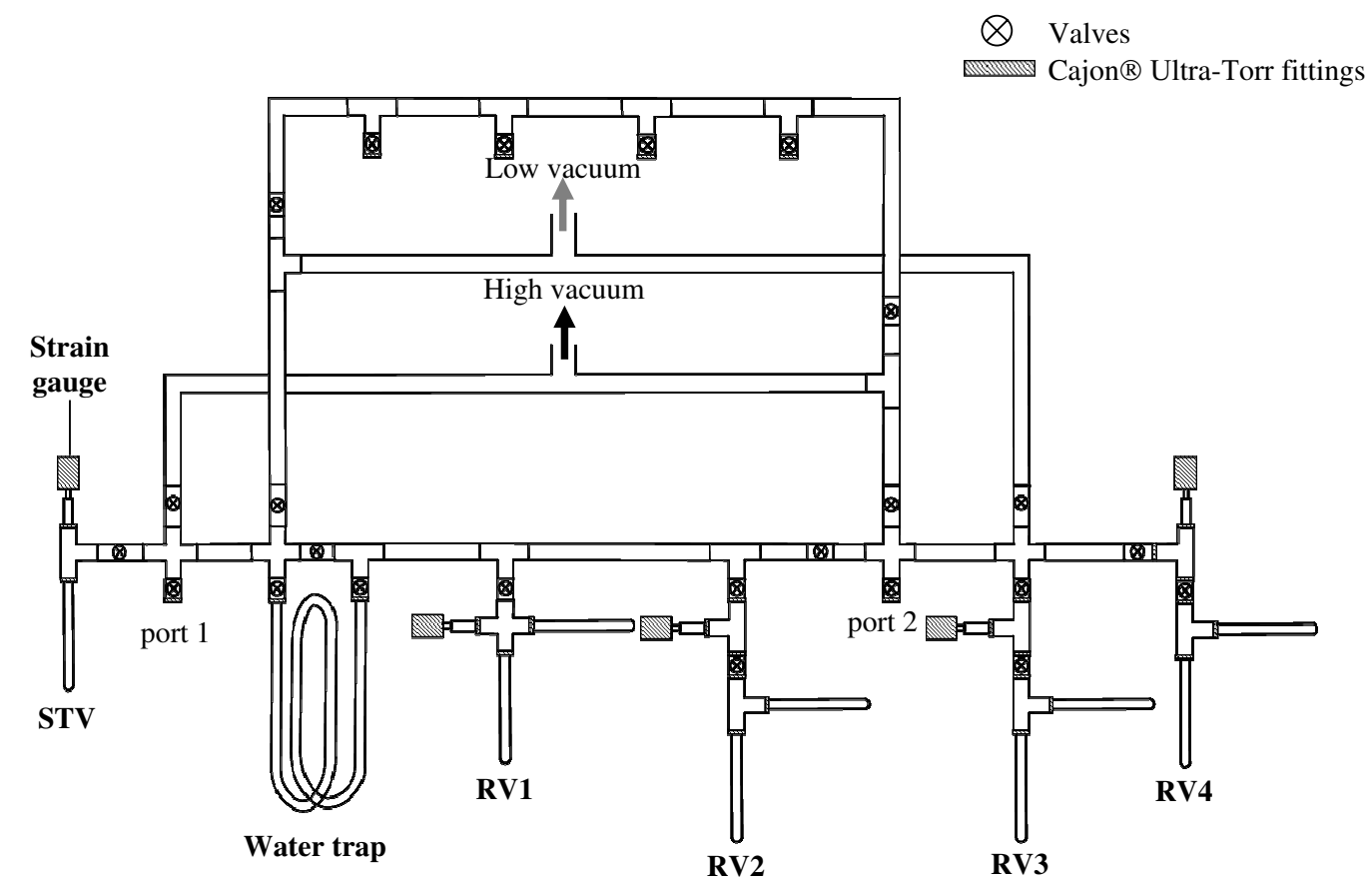

Figure 1 Schematic diagram of the new vacuum line. RV1-4: graphitization reaction vessels; STV: calibrated standard volume; measurement of low vacuum by Pirani gauge, high vacuum by wide range gauge.

small fans were installed next to the gauge. The purchase of much lighter and smaller furnaces (Carbolite) allowed us to modify the graphitization vessel setup in order to reduce the volume of the graphitization vessels, increasing the starting pressure of $\mathrm{CO}_{2}$ samples and optimizing reaction yields. The reactors are now positioned in a cross or T-shaped arrangement with the Fe furnace positioned horizontally and the Zn furnace vertically (Figure 2, designs B and C). These designs also reduce the number of Cajon fittings required and hence the potential for leaks, especially at longer reaction times. Design $\mathrm{C}$ isolates the transducer during graphitization, minimizing possible contamination to/from the transducer, and has the smallest volume $(3 \mathrm{~mL})$ of the 3 designs. All reaction vessels were modified to design C except RV1, where the transducer volume could not be isolated due to space limitations. RV1 has a total volume of $6 \mathrm{~mL}$.

\section{Modification of Graphitization Procedure}

The graphite samples were assessed on the basis of the following criteria: a) graphitization yield and reaction time; b) simplicity of transferring graphite to target holder; c) targets should achieve a minimum ${ }^{12} \mathrm{C}$ current of $20 \mu \mathrm{A}$; and d) background levels.

\section{a) Graphite Yield and Reaction Time}

To avoid contamination from adsorbed $\mathrm{CO}_{2}$ or particulates (Vandeputte et al. 1998; Kirner et al. 1995; Verkouteren et al. 1987), all glass tubes are cleaned at $600{ }^{\circ} \mathrm{C}$ prior to the graphitization and are stored in a gas-tight box over Carbosorb ${ }^{\circledR}$ (Fisher Scientific). Approximately $200 \mathrm{mg}$ of powdered zinc (Fisher Scientific, analytical grade) and iron powder (various suppliers, Table 1) in a ratio of 1:2 ( $\mathrm{C}$ to $\mathrm{Fe})$ is used. The metals are loaded into the reaction vessels, which are then evacuated. The zinc furnace is kept at $420^{\circ} \mathrm{C}$, and the iron furnace is kept at $620-630^{\circ} \mathrm{C}$. The metals are heated 


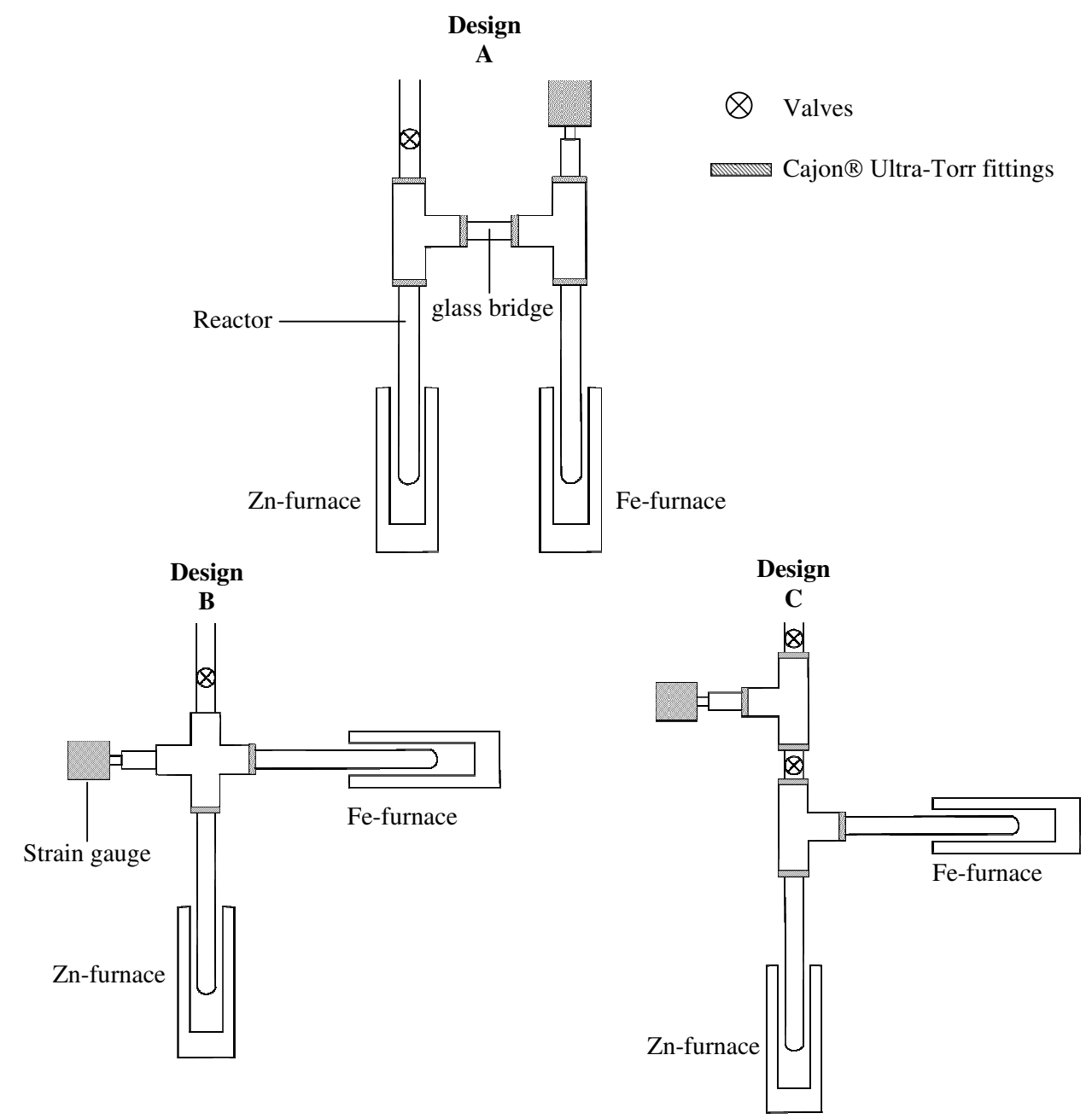

Figure 2 Schematic diagram of the different $\mathrm{CO}_{2}$ reduction systems used. A) shows the initial setup used, B) the setup of RV1, and C) of RV2-4 presently used for graphitization.

for 10 min, pumping first on the low vacuum and then on the high vacuum. The evacuated reaction vessel is isolated and checked for leaks, and the transducer readout records the baseline pressure. The $\mathrm{CO}_{2}$ is transferred into the reactors. Conversion of $\mathrm{CO}_{2}$ to graphite (Slota et al. 1987) is calculated as a percent yield based on the original and final gas pressures within the reactor. A minimum yield of $95 \%$ is required to avoid the possibility of fractionation.

\section{b) and c) Choice of Catalyst and Carbon to Iron Ratio}

The main challenge in measuring small graphite targets is to produce a high-quality target with minimum contamination that performs well during AMS analysis. Our aims were the following: to use a constant carbon to iron ratio to minimize contamination, as background ${ }^{14} \mathrm{C}$ levels can increase with increasing Fe weight (Dee and Bronk Ramsey 2000; Vandeputte et al. 1998); to maximize the graphitization yield; to ensure that the Fe-graphite mixture can be readily and completely transferred into the aluminium cathode target holders; and to achieve a satisfactory performance of the target 
Table 1 Different iron catalysts tested for graphitization.

\begin{tabular}{|c|c|c|c|c|c|c|}
\hline \multirow[b]{2}{*}{ Catalyst } & \multirow[b]{2}{*}{ Supplier } & \multirow[b]{2}{*}{ Specification } & \multicolumn{2}{|c|}{$\begin{array}{c}\text { Samples } \\
500-100 \mu \mathrm{g} \mathrm{C}\end{array}$} & \multicolumn{2}{|c|}{$\begin{array}{c}\text { Samples } \\
<100 \mu \mathrm{g} \mathrm{C}{ }^{\mathrm{a}}\end{array}$} \\
\hline & & & $\begin{array}{l}\text { Reaction } \\
\text { yield } \\
\mathrm{C}: \mathrm{Fe}=1: 2\end{array}$ & $\begin{array}{l}\text { Reaction } \\
\text { yield } \\
\mathrm{C}: \mathrm{Fe}=1: 3^{\mathrm{a}}\end{array}$ & $\begin{array}{l}\text { Reaction } \\
\text { yield } \\
\mathrm{C}: \mathrm{Fe}=1: 2\end{array}$ & $\begin{array}{l}\text { Reaction } \\
\text { yield } \\
\mathrm{C}: \mathrm{Fe}=1: 3^{\mathrm{a}}\end{array}$ \\
\hline $\mathrm{Fe} 1$ & $\begin{array}{l}\text { Prolabo }^{\mathrm{b}} \\
\text { R.P. Normapur }\end{array}$ & $\begin{array}{l}\text { iron powder, } \\
<10 \mu \mathrm{m}, \\
>99.50 \% \text { purity }\end{array}$ & $>99 \%$ & $>99 \%$ & $>95 \%$ & $>95 \%$ \\
\hline $\mathrm{Fe} 2$ & $\mathrm{BDH}$ & $\begin{array}{l}\text { iron powder, } \\
<10 \mu \mathrm{m}, \\
>99.90 \% \text { purity }\end{array}$ & $>99 \%$ & $>99 \%$ & $>95 \%$ & $>95 \%$ \\
\hline $\mathrm{Fe} 3$ & Goodfellow & $\begin{array}{l}\text { iron powder, } \\
<800 \mu \mathrm{m} \text {, } \\
>99.99 \% \text { purity }\end{array}$ & $95-99 \%$ & $95-99 \%$ & $>95 \%$ & $>95 \%$ \\
\hline $\mathrm{Fe} 4$ & $\begin{array}{l}\text { Riedel-de } \\
\text { Haen }\end{array}$ & $\begin{array}{l}\text { iron powder, } \\
<150 \mu \mathrm{m} \text {, } \\
>99.50 \% \text { purity }\end{array}$ & $60-80 \%$ & $60-80 \%$ & n.t. ${ }^{d}$ & n.t. \\
\hline $\mathrm{Fe} 5$ & Alfa Aesar & $\begin{array}{l}\text { iron powder, } \\
<150 \mu \mathrm{m} \text {, } \\
>99.90 \% \text { purity }\end{array}$ & $20-50 \%$ & $20-50 \%$ & n.t. & n.t. \\
\hline
\end{tabular}

${ }^{\mathrm{a}}$ Graphitization for samples $<100 \mu \mathrm{g}$ C was only tested when yield at higher carbon content was $>95 \%$.

${ }^{b}$ Used for standard graphitization procedure in the facility.

${ }^{c}$ n.t. $=$ not tested.

${ }^{\mathrm{d}}$ Purity refers to trace metal contents only.

during AMS measurement. Table 1 summarizes the different catalysts tested. Fe 1, routinely used for samples larger than $500 \mu \mathrm{g} \mathrm{C}$, gives a good background $(0.2 \mathrm{pMC}$; based on inorganic carbon blank) and reaction yields $>99 \%$. However, being finely divided, it is difficult to quantitatively transfer and consolidate into targets $<500 \mu \mathrm{g} \mathrm{C}$. The use of magnets and shorter glass tubes has not improved the procedure. We tested a variety of $\mathrm{Fe}$ catalysts in order to meet the criteria required to produce high-quality targets of $<500 \mu \mathrm{g} \mathrm{C} . \mathrm{CO}_{2}$ used to prepare the targets was obtained from 2-L bulk gases.

The optimum ratio of sample carbon to catalyst was determined by current AMS measurements. The overall current output, as well as the measurement time, were taken into account (target had to persist long enough for a minimum of 3 runs at $20-25 \mu \mathrm{A}$ ).

\section{d) System Background Levels and Carbonate Process Background}

Two-liter batches of $\mathrm{CO}_{2}$ were prepared from Iceland spar calcite to minimize contamination due to hydrolysis processing and provide isotopically homogeneous $\mathrm{CO}_{2}$. To independently assess the background contribution of hydrolysis of small inorganic samples, individual carbonate samples were hydrolyzed and compared to the results obtained from the bulk gas. To minimize the contamination during the graphite handling and storage due to exposure to atmospheric $\mathrm{CO}_{2}$, the reaction vessels are removed from the vacuum line after venting the system with nitrogen (Air Products, 99.999\%) and the unpelletized graphites are stored in an air-tight box over Carbosorb (Fisher Scientific). Graphites are only exposed to the atmosphere during pelletizing as the targets are stored subsequently in gas-tight vials under argon (99.999\%, CK gases). 
Figure 3 shows the vessels routinely used for hydrolysis of small carbonate processing. The vacuum valves are supplied by Kontes ${ }^{\circledR}$ (HI-VAC ${ }^{\circledR}$, VWR International). The $\mathrm{CO}_{2}$ is prepared by $\mathrm{H}_{3} \mathrm{PO}_{4}$ hydrolysis of $\mathrm{HCl}$-etched carbonates (McCrea 1950). One to $2 \mathrm{~mL}$ of $\mathrm{H}_{3} \mathrm{PO}_{4}$ is filled in the side arm, and the sample in the vertical part of the vessel, which is then evacuated and removed from the vacuum line and placed in a water bath. After reaching the reaction temperature of $25{ }^{\circ} \mathrm{C}$, the acid is added to the sample by tilting the vessel. The reaction time is $16 \mathrm{hr}$. During storage, the reaction vessels are always kept evacuated to ensure that O-rings are completely outgassed and to avoid $\mathrm{CO}_{2}$ adsorption to the glass surface.

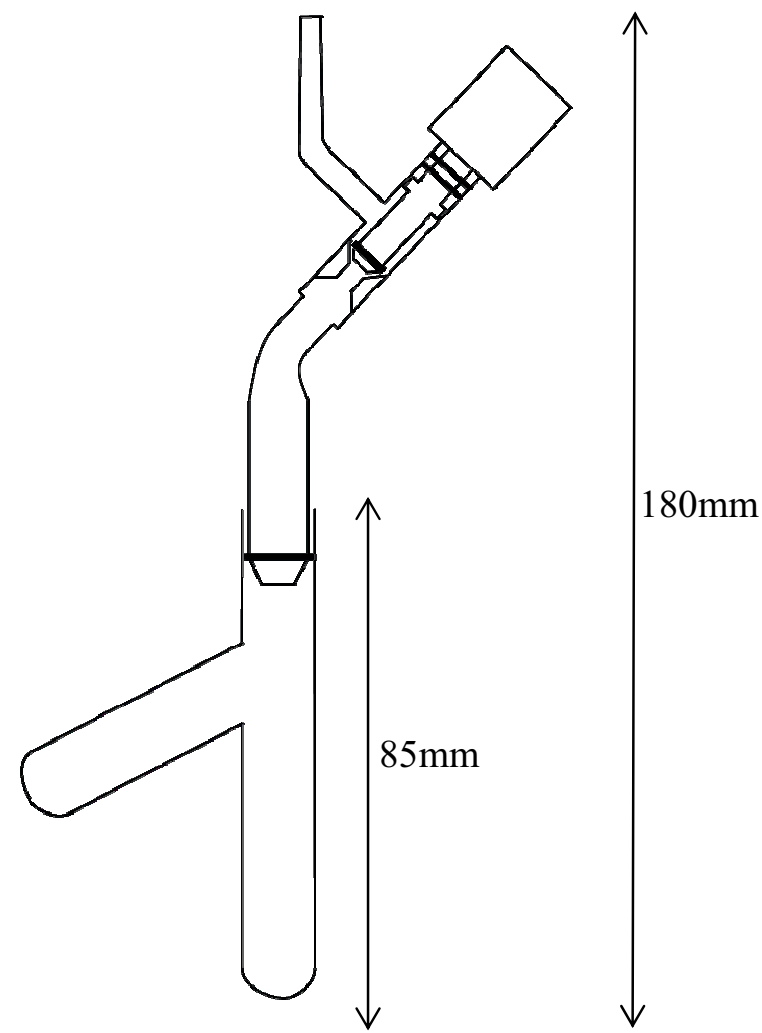

Figure 3 Schematic drawing of the hydrolysis vessel; left arm of lower part contains the acid, the vertical one the sample. Valves are supplied by Kimble-Kontes.

\section{Fractionation During Graphitization Procedure for Small Samples}

Measuring small graphite targets by AMS has revealed a deviation in their carbon isotopic ratio compared to higher C masses (Nadeau et al. 1987; van der Borg et al. 1997). Mass fractionation may occur in the processes of the graphitization, ion production in the source (Nadeau et al. 1987), and stripping (Hofmann et al. 1984). To estimate the fractionation introduced during the graphitization process, a series of graphite samples with masses in the range of 1600 to $50 \mu \mathrm{g} \mathrm{C}$ were prepared from bulk gas of NIST Oxalic acid II, combusted back to $\mathrm{CO}_{2}$, and then analyzed by isotope ratio mass spectrometry (IRMS). The dual-inlet mass spectrometer with a multiple beam collection facility (VG OPTIMA) was calibrated with international reference materials to a precision of $0.1 \%$ $\delta^{13} \mathrm{C}_{\mathrm{VPDB}}$. Quoted $\delta^{13} \mathrm{C}$ values are reported relative to VPDB by reference to Craig (1957) and 
Coplen (1995). The $\delta^{13} \mathrm{C}$ values obtained were then compared with the original $\delta^{13} \mathrm{C}$ values of the bulk gas aliquots. This was done for both graphite line designs (Figure 2, designs $\mathrm{A}$ and $\mathrm{B}+\mathrm{C}$ ).

\section{RESULTS AND DISCUSSION}

\section{Choice of Catalyst and Carbon to Iron Ratio}

Changes in the nature and quantity of Fe powder have a marked effect on the graphite target formed. In all cases, carbon deposition occurred, though the textural gradation varied with the different $\mathrm{Fe}$ powders used (Figure 4). Catalysts $\mathrm{Fe} 1$ and $\mathrm{Fe} 2$, with high surface to volume ratios, yielded a high reaction rate. However, the graphite formed was abundant and fluffy and difficult to quantitatively transfer to the target holder. Graphite produced with the coarser catalysts, Fe 4 and 5, can be completely transferred to the target holder, but the reaction yield is not satisfactory, even at higher C:Fe ratios and reaction times up to $24 \mathrm{hr}$. The optimum results for all criteria for preparing graphite targets down to $30 \mu \mathrm{g} \mathrm{C}$ are obtained by using catalyst $\mathrm{Fe} 3$ with a maximum particle size of $800 \mu \mathrm{m}$. The graphitization yield is $>95 \%$ and the particle size of Fe is large enough to transfer it completely into the target holder; nevertheless, reaction times are rather long at 18-20 hr. The decreased reaction rate with high-purity iron has been attributed to a lower C-nuclei abundance (Vandeputte et al. 1998). Figure 4 shows the surface of the catalyst $\mathrm{Fe} 1$ and $\mathrm{Fe} 3$ before and after graphitization. SEM images clearly show the much finer grain size of $\mathrm{Fe} 1$ compared to $\mathrm{Fe}$ 3. Carbon deposition on $\mathrm{Fe} 1$ seems to be much more finely divided than on $\mathrm{Fe} 3$, probably due to the higher particle size and the higher sample to iron ratio of Fe 3. The optimum C:Fe ratio is 1:2 (by mass) for $500 \mu \mathrm{g} \mathrm{C}$ and 1:3.0 to $1: 3.5$ (by mass) for $30-500 \mu \mathrm{g} \mathrm{C}$.

\section{System and Inorganic Process Blank}

Measurements were made on graphite masses of 30 to $1600 \mu \mathrm{g}$ C. Figure 5 summarizes the measurements at low current (20-25 $\mu \mathrm{A})$ with a minimum precision of 3-5\% for samples $<150 \mu \mathrm{g} \mathrm{C}$. Comparably sized Oxalic acid II standards were prepared and used to calculate ${ }^{14} \mathrm{C} /{ }^{13} \mathrm{C}$ pMC.${ }^{14} \mathrm{C}$ results are expressed in terms of percent modern carbon (pMC). Results have not been corrected for machine background.

We observed a similar trend in background values to past literature (e.g. Donahue et al. 1997; Pearson et al. 1998; Hua et al. 2004; Czernik and Goslar 2001). Although Donahue et al. (1997) observed an increase of background levels below $1 \mathrm{mg} \mathrm{C}$ showing a clear inverse mass dependency of samples $<1 \mathrm{mg} \mathrm{C}$, the background observed in our study remains constant down to a sample size of $150 \mu \mathrm{g}$ and increases significantly below $150 \mu \mathrm{g}$. This is possibly due to the fact that very small graphite targets $(<150 \mu \mathrm{g} \mathrm{C})$ are more prone to adsorbed atmospheric $\mathrm{CO}_{2}$ in addition to a constant amount of contamination, probably present in the catalyst. As the lifetime of targets $<150 \mu \mathrm{g} \mathrm{C}$ during analysis is critically short, surface contamination cannot be removed as initial sputtering is not possible with such small targets. Targets obtained from ${ }^{14} \mathrm{C}$-dead bulk gas have an average value of $0.13 \pm 0.06 \mathrm{pMC}(n=14)$ above $150 \mu \mathrm{g} \mathrm{C}$ and $0.28 \pm 0.10 \mathrm{pMC}(n=11)$ for $30-150 \mu \mathrm{g} \mathrm{C}$ (values based on mean of individual measurements and associated standard deviation). Blanks obtained from individual hydrolysis reactions are slightly higher but still overlap with system blanks at the 1$\sigma$ confidence limit: $0.17 \pm 0.04 \mathrm{pMC}(n=3)>150 \mu \mathrm{g} \mathrm{C}$ and $0.32 \pm 0.11 \mathrm{pMC}(n=2) 30-150 \mu \mathrm{g} \mathrm{C}$. This may be due to contaminant $\mathrm{CO}_{2}$ adsorbed in the reaction vessels and/or contamination added to the etched carbonate during grinding and weighing. As the lifetime of targets $<150 \mu \mathrm{g} \mathrm{C}$ can become critically short and as the background increases significantly, only targets $>150 \mu \mathrm{g} \mathrm{C}$ produce consistently reliable AMS data at present. 
A) Fe 1, untreated

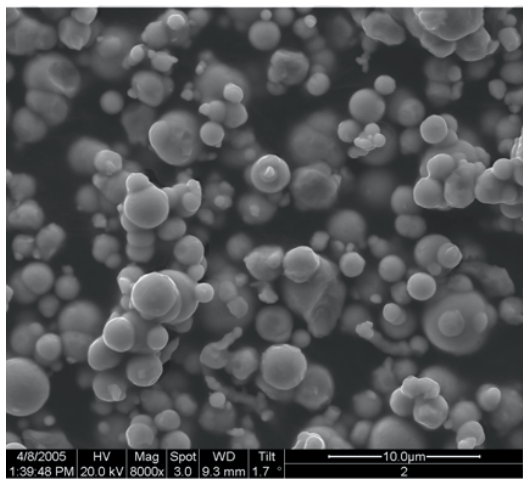

C) Fe 3, untreated

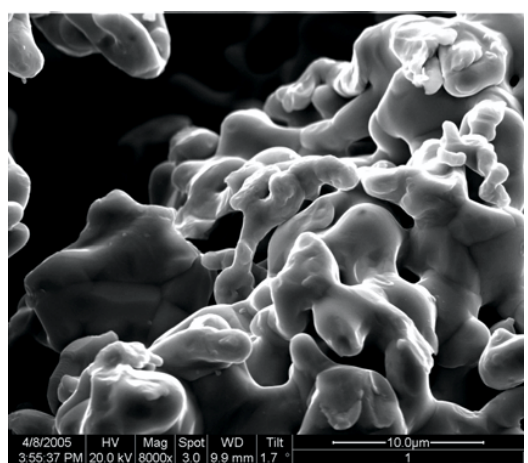

B) Fe 1, with deposited carbon

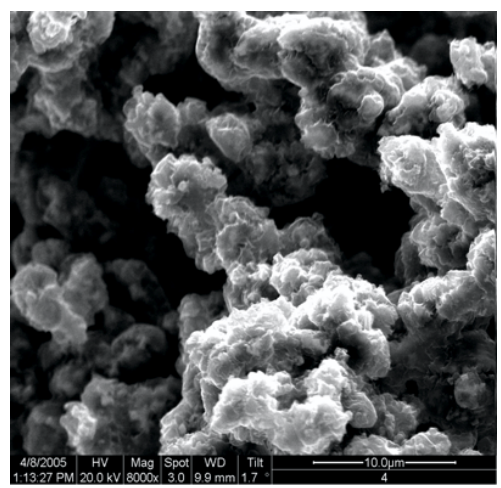

D) Fe 3, with deposited carbon

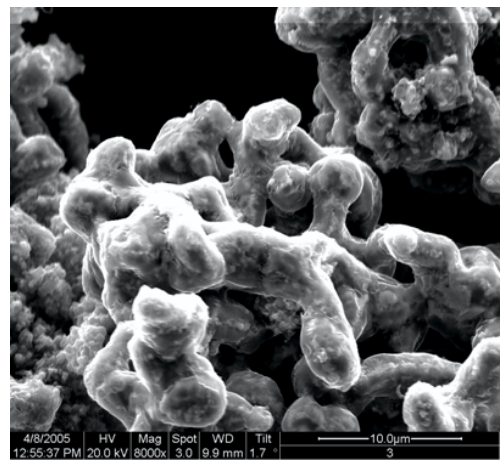

Figure 4 SEM images of catalyst Fe 1 and 3 before and after graphitization. Images taken at a magnification factor of 8000 (Cambridge Instruments S3600 SEM with Oxford Instruments ISIS microanalysis system). Samples of carbon are coated for imaging. SEM images were taken at the Division of Earth Sciences at the University of Glasgow.

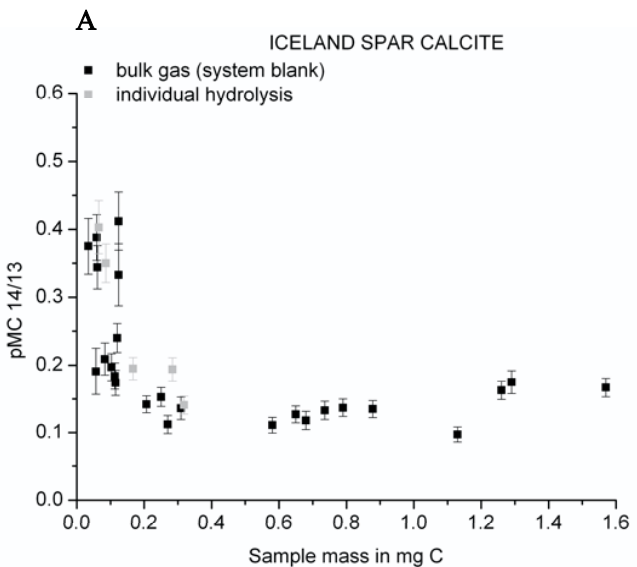

B

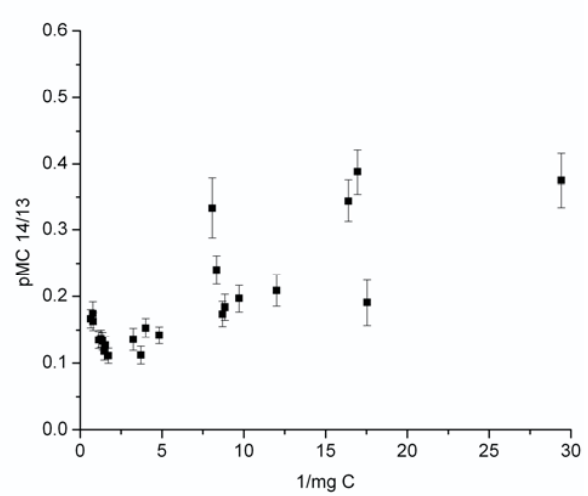

Figure 5 a) pMC based on 14/13 ratio versus carbon content in AMS target; black data points obtained from targets of Iceland spar calcite (ISC) bulk gas, gray data points from individual hydrolysis of ISC; b) pMC based on 14/13 ratio versus inverse carbon mass in target; data points obtained from bulk gases plotted. 
To estimate the amount of contamination introduced during $\mathrm{CO}_{2}$ handling, the theoretical number of ${ }^{14} \mathrm{C}$ and ${ }^{12} \mathrm{C}$ atoms in the targets was calculated (Figure 6). Although average contaminants can apparently be quite old ( ${ }^{14} \mathrm{C}$ content of 27-44 pMC) (Mueller and Muzikar 2002; Brown and Southon 1997), we have assumed for our calculations a ${ }^{14} \mathrm{C}$ to $\mathrm{C}$ ratio of $1.1756 \mathrm{E}-12$ (modern contamination). This assumption is based on the fact that there are no known potential "old" $\mathrm{CO}_{2}$ sources in the laboratory (e.g. dry ice), and that oil-free pump systems are used. Studies using known-age standards are currently being undertaken to elucidate the actual ${ }^{14} \mathrm{C}$ activity of the contaminant.

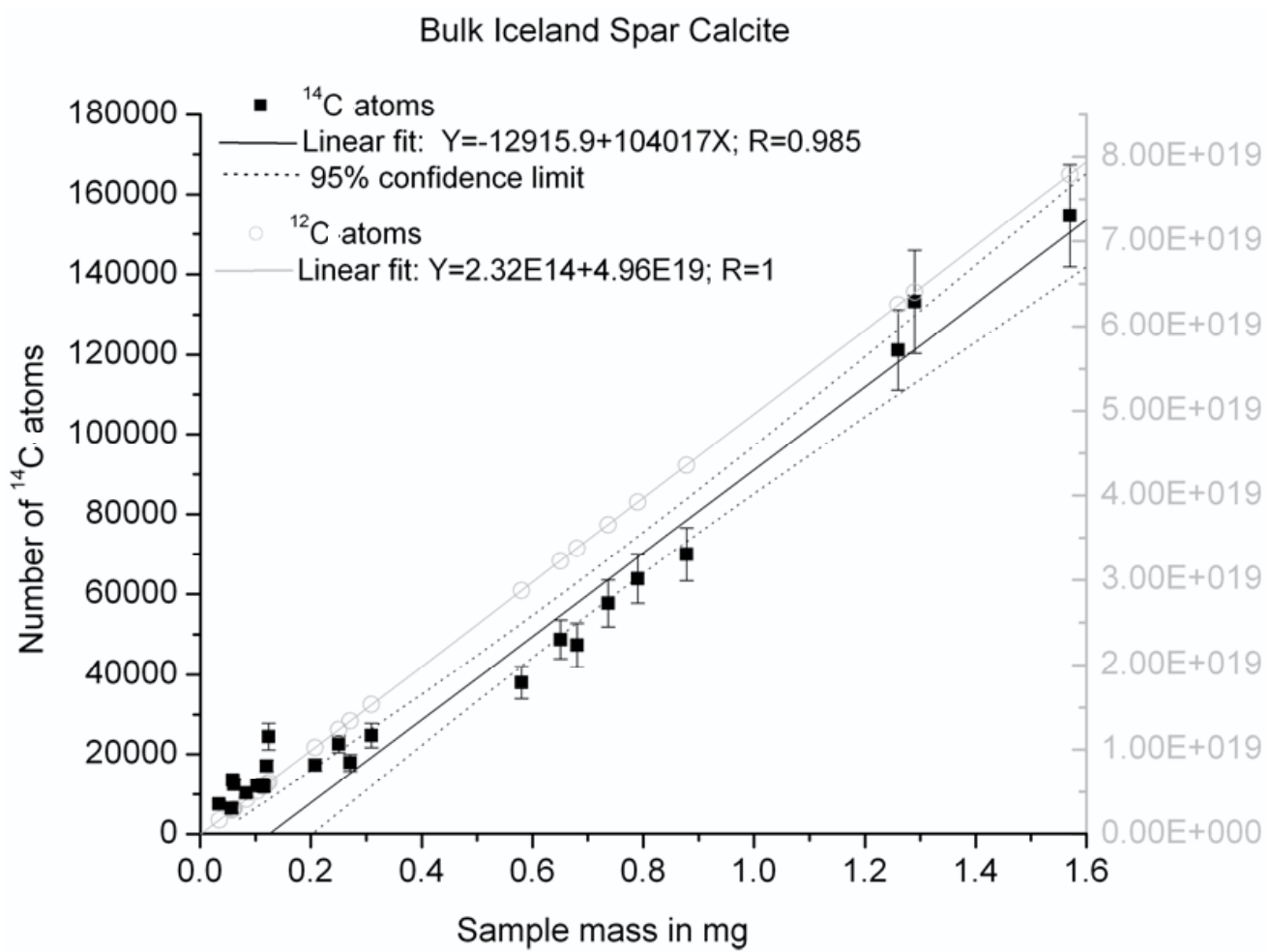

Figure 6 Calculated number of ${ }^{14} \mathrm{C}$ and ${ }^{12} \mathrm{C}$ atoms in targets of bulk Iceland spar calcite versus sample mass; black data points: ${ }^{14} \mathrm{C}$ atoms based on assumption that ${ }^{14} \mathrm{C} / \mathrm{C}=1.1756 \mathrm{E}-12$; gray data points: ${ }^{12} \mathrm{C}$ atoms in the sample.

The calculated number of ${ }^{14} \mathrm{C}$ atoms shows that a constant amount of carbon, probably in the iron, is present in samples $>150 \mu \mathrm{g} \mathrm{C}$; thus, the background is mass independent, whereas smaller samples seem to indicate an inverse mass dependence (Donahue et al. 1997). The calculated number of ${ }^{12} \mathrm{C}$ atoms shows the expected linearity of atom number and sample mass. During pelletizing, the freshly prepared graphites are exposed to the atmosphere for a short period of time. Additional contact with the air occurs during the loading procedure of the ion source. As graphite is highly adsorptive, brief exposure to atmospheric $\mathrm{CO}_{2}$ may be sufficient to increase the background. A solution to overcome these potential contamination sources would be to pelletize and load the sample wheel in an inert atmosphere $\left(\mathrm{N}_{2}\right.$ or Ar). To clarify whether there is a significant inverse mass dependence for samples $<150 \mu \mathrm{g} \mathrm{C}$, measured ${ }^{14} \mathrm{C}$ activity (pMC) is plotted against $1 /$ mass (Figure $5 \mathrm{~b}$ ). The data $<150 \mu \mathrm{g} \mathrm{C}$ cannot be described by a simple linear fit, and contamination at these sample masses is variable. We are currently trying to further improve the preparation of inorganic $\mathrm{C}$ samples with the aim of obtaining reproducibly low background levels. The gas ion source at the SUERC AMS facil- 
ity is currently under development with the aim of analyzing samples $<100-150 \mu \mathrm{g} \mathrm{C}$ and avoiding contamination due to graphite target production.

\section{Fractionation During Graphitization Procedure for Small Samples}

For graphites $>200 \mu \mathrm{g} \mathrm{C}$, there is no fractionation within an overall analytical error of $\delta^{13} \mathrm{C}=0.5 \%$. The measured $\delta^{13} \mathrm{C}$ values for all graphite reactor designs (Figures 7a and $7 \mathrm{~b}$ ) indicates some isotopic fractionation (depletion) in the graphitization process of samples $<200 \mu \mathrm{g} \mathrm{C}$, presumably due to an incomplete reaction at very low pressure, although all reactions yields were higher than $95 \%$. For masses below $200 \mu \mathrm{g} \mathrm{C}$, the $\delta^{13} \mathrm{C}$ values measured for combusted graphites deviate by $0.8 \pm 0.1 \%$ o $(n=3)$ from the bulk gas value for vessel design $\mathrm{A}$, and $0.7 \pm 0.1 \% o(n=3)$ for designs $\mathrm{B}$ and $\mathrm{C}$; hence, there is no significant difference between the different designs. There was no difference in $\delta^{13} \mathrm{C}$ values observed between RV1 and RV2-4. At low gas pressures, the calculated reaction yield may well be close to $100 \%$, but very small amounts of unreacted $\mathrm{CO}_{2}$, which cannot be measured with the gauges used, are obviously sufficient to introduce the fractionation observed. The observed depletion is within the measurement error of the $\delta^{13} \mathrm{C}$ values obtained by AMS (1\%o).

\section{Design A}

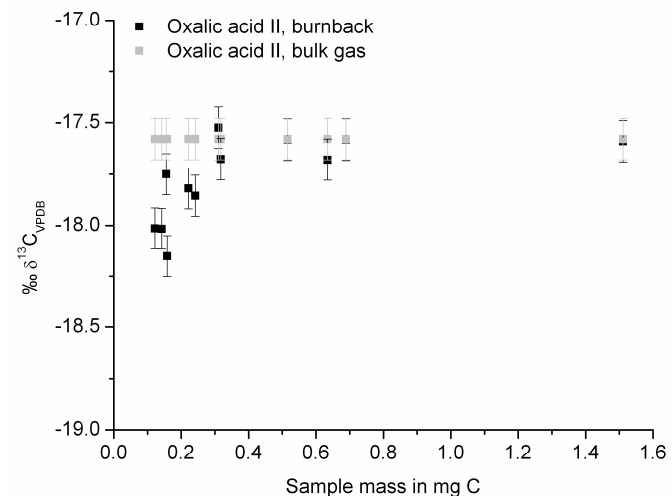

Design B\&C

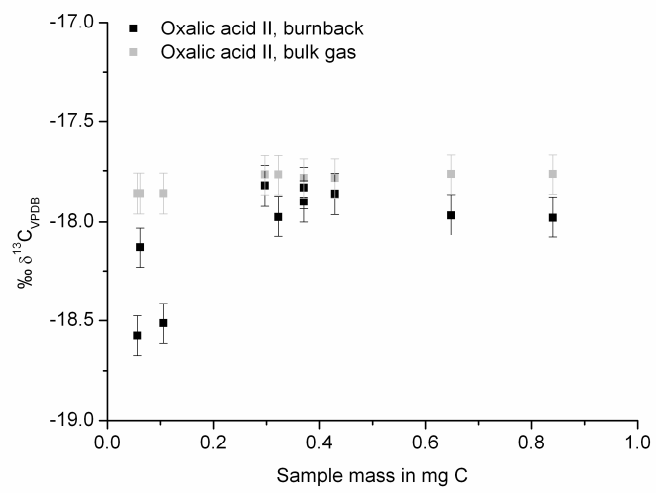

Figure 7 Deviation in ${ }^{13} \mathrm{C} /{ }^{12} \mathrm{C}$ ratio expressed as $\delta^{13} \mathrm{C}$ values; gray data points: $\delta^{13} \mathrm{C}$ obtained from oxalic acid II bulk gas (individual aliquots of variable size obtained from a 2-L bulk gas); black data points: $\delta^{13} \mathrm{C}$ obtained from graphitized oxalic acid II bulk gas aliquots after burnback with $\mathrm{CuO}$. Measurement precision is \pm 0.1 . Design $\mathrm{A}$ : $\mathrm{H}$-shaped design of $\mathrm{Zn}$ and Fe furnace; designs B\&C: $\mathrm{Zn}$ furnace placed vertical to Fe furnace. Different bulk gas preparations were used but these were within the $0.5 \%$ o precision for repeat combustion and analysis.

\section{CONCLUSION}

A new purpose-built high-vacuum line with a modified graphitization procedure allows us to successfully prepare and analyze graphite samples down to a size of $150 \mu \mathrm{g} \mathrm{C}$. This is a significant reduction in the sample size required compared with our routine sample sizes of $500 \mu \mathrm{g} \mathrm{C}$. The process routinely applied to produce targets larger than $500 \mu \mathrm{g} C$ has been optimized to produce smaller graphites which could be successfully analyzed by the SUERC AMS facility. A coarser grained iron catalyst improved quantitative transfer and consolidation of graphite into an AMS target and a higher sample carbon to iron ratio of 1:3 to 1:3.5 produced more consistent performance during AMS analysis. Graphite reaction vessels were modified to a design less prone to leaks and with a smaller volume to increase initial reaction pressure. System blanks (values based on the mean of individual measurement and associated standard deviation) using bulk gases nearly double from 
$0.13 \pm 0.06 \mathrm{pMC}(>150 \mu \mathrm{g} \mathrm{C})$ to $0.28 \pm 0.11 \mathrm{pMC}(30-150 \mu \mathrm{g} \mathrm{C})$ as small graphite targets are more prone to contamination. Process backgrounds for inorganic samples are similar and not significantly different: $0.17 \pm 0.04 \mathrm{pMC}(>150 \mu \mathrm{g} \mathrm{C})$ and $0.32 \pm 0.11 \mathrm{pMC}(30-150 \mu \mathrm{g} \mathrm{C})$. As the background at present becomes more dominant and variable below $150 \mu \mathrm{g} \mathrm{C}$ and target lifetime can become critical at sample sizes lower than $150 \mu \mathrm{g} \mathrm{C}$, we currently only process samples down to a minimum of $150 \mu \mathrm{g} \mathrm{C}$. Although sample sizes lower than $150 \mu \mathrm{g} \mathrm{C}$ can be analyzed, the uncertainty of the measured ${ }^{14} \mathrm{C}$ activity, especially if the sample ${ }^{14} \mathrm{C}$ activity is close to background, becomes much more important. We suggest that for inorganic background samples $>150 \mu \mathrm{g} \mathrm{C}$, a minimum uncertainty in the background of $\pm 0.1 \mathrm{pMC}$ should be included. For sample sizes $<150 \mu \mathrm{g} \mathrm{C}$, an uncertainty of $\pm 0.2 \mathrm{pMC}$ and a consequent dating limit of $0.56-0.84 \mathrm{pMC}$ accommodates the fact that individual measurement errors are much larger and that the scatter of individual points is more pronounced for smaller samples. The modified graphitization procedure introduces a minor mass fractionation (depletion) of $\delta^{13} \mathrm{C}_{\mathrm{VPDB}}=0.7 \pm 0.1 \%$ below $200 \mu \mathrm{g}$ C. This is within the uncertainty of on-line $\delta^{13} \mathrm{C}$ measurement based on known activity standards and required for small samples for which there is insufficient material for an independent $\delta^{13} \mathrm{C}$ measurement. Further fractionation may occur during AMS analysis. We are currently developing the gas ion source for analysis of samples $<150 \mu \mathrm{g} \mathrm{C}$. The limit to sample size of organic samples is also being addressed.

\section{ACKNOWLEDGMENTS}

Authors would like to thank the anonymous reviewer for critical comments, which improved the initial manuscript, and Prof Marian Scott for scientific support.

\section{REFERENCES}

Brown TA, Southon JR. 1997. Corrections for contamination background in AMS ${ }^{14} \mathrm{C}$ measurements. Nuclear Instruments and Methods in Physics B 123: 208-13.

Coplen TB. 1995. New IUPAC guidelines for the reporting of stable hydrogen, carbon and oxygen isotoperatio data. Journal of Research of the National Institute of Standards and Technology 100(3):285-95.

Czernik J, Goslar T. 2001. Preparation of graphite targets in the Gliwice radiocarbon laboratory for ${ }^{14} \mathrm{C}$ AMS dating. Radiocarbon 43(2A):283-91.

Dee M, Bronk Ramsey C. 2000. Refinement of graphite target production at ORAU. Nuclear Instruments and Methods in Physics B 172:449-53.

Donahue DJ, Linick TW, Jull AJT. 1990. Isotope-ratio and background corrections for accelerator mass spectrometry radiocarbon measurements. Radiocarbon 32(2):135-42.

Donahue DJ, Beck JW, Biddulph D, Burr GS, Courtney C, Damon PE, Hatheway AL, Hewitt L, Jull AJT, Lange T, Maddock R, McHargue LR, O'Malley JM, Toolin LJ. 1997. Status of the NSF-Arizona AMS laboratory. Nuclear Instruments and Methods in Physics Research B 123:51-6.

Freeman S, Xu S, Schnabel C, Dougans A, Tait A, Kitchen R, Klody G, Loger R, Pollock T, Schroeder J, Sunquist M. 2004. Initial measurements with the SUERC accelerator mass spectrometer. Nuclear Instruments and Methods in Physics B 223-224:195-8.
Freeman S, Bishop P, Bryant C, Cook G, Fallick A, Harkness D, Metcalfe S, Scott M, Scott R, Summerfield M. 2004. A new environmental science AMS laboratory in Scotland. Nuclear Instruments and Methods in Physics B 223-224:3134.

Hua Q, Jacobsen GE, Zoppi U, Lawson EM, Williams AA, Smith AA, McGann MJ. 2004. Progress in radiocarbon target preparation at the ANTARES AMS Centre. Radiocarbon 43(2A):275-82.

Kirner DL, Taylor RE, Southon JR. 1995. Reduction in background of microsamples for AMS ${ }^{14} \mathrm{C}$ dating. $R a$ diocarbon 37(2):697-704.

McCrea JM. 1950. On the isotopic chemistry of carbonates and a paleotemperature scale. Journal of Chemical Physics 18:849-57.

McNichol AP, Gagnon AR, Jones GA, Osborne EQ. 1992. Illumination of a black box: analysis of gas composition during graphite target preparation. Radiocarbon 34(3):321-9.

Mueller K, Muzikar P. 2002. Quantitative study of contamination in AMS. Nuclear Instruments and Methods in Physics Research B 197:128-33.

Nadeau M-J, Kieser WE, Beukens RP, Litherland AE. 1987. Quantum mechanical effects on sputter source isotope fraction. Nuclear Instruments and Methods in Physics B 29:83-6.

Pearson A, McNichol AP, Schneider RJ, von Reden KF. 1998. Microscale AMS ${ }^{14} \mathrm{C}$ measurement at NOSAMS. Radiocarbon 40(1):61-75. 
Pohlmann JW, Knies DL, Grabowski KS, De Truck TM, Treacy DJ, Coffin RB. 2000. Sample distillation/ graphitization system for carbon pool analysis by accelerator mass spectrometry (AMS). Nuclear Instruments and Methods in Physics B 172:428-33.

Slota PJ, Jull AJT, Linick TW, Toolin LJ. 1987. Preparation of small samples for ${ }^{14} \mathrm{C}$ accelerator targets by catalytic reduction of CO. Radiocarbon 29(2):303-6.

Vandeputte K, Moens L, Dams R, van der Plicht J. 1998. Study of the ${ }^{14} \mathrm{C}$-contamination potential of C-impurities in $\mathrm{CuO}$ and Fe. Radiocarbon 40(1):103-10.

van der Borg K, Alderliesten C, de Jong AFM, van den Brink A, de Haas AP, Kersemaekers HJH, Raaymak- ers JEMJ. 1997. Precision and mass fractionation in ${ }^{14} \mathrm{C}$ analysis with AMS. Nuclear Instruments and Methods in Physics Research B 123:97-101.

Verkouteren RM, Klouda GA, Currie LA, Donahue DJ, Linick TW. 1987. Preparation of microgram samples on iron wool for radiocarbon analysis via accelerator mass spectrometry: a closed system approach. $\mathrm{Nu}$ clear Instruments and Methods in Physics Research B 29:41-4.

Vogel JS, Nelson DE, Southon JR. ${ }^{14} \mathrm{C}$ background levels in an accelerator mass spectrometry system. Radiocarbon 29(3):323-33.

\section{APPENDIX}

\begin{tabular}{|c|c|}
\hline Component & Description / Supplier \\
\hline Turbomolecular pump & $\begin{array}{l}\text { BOC Edwards, West Sussex; EXT compound molecular pump with } \\
\text { incorporated controller }\end{array}$ \\
\hline Scroll pump & BOC Edwards; West Sussex; XDS10C \\
\hline $\begin{array}{l}\text { Electropolished } \\
\text { stainless steel }\end{array}$ & $\begin{array}{l}\text { According to ASTM A269/A632, equal. DIN } 17458 \text { material } 316 \mathrm{~L} / \\
1.04404 ; 1 / 4^{\prime \prime} \mathrm{O} / \mathrm{D} \times 0.036^{\prime \prime} \mathrm{W} / \mathrm{T} \text { and } 1 / 2^{\prime \prime} \mathrm{O} / \mathrm{D} \times 0.049^{\prime \prime} \mathrm{W} / \mathrm{T} \text {; } \\
\text { inner surface roughness max. } 25 \mu \mathrm{m} \text {; Dockweiler, Wrexham }\end{array}$ \\
\hline Glass tubes & Quartz glass, $6 \mathrm{~mm} \mathrm{ID,} 100 \mathrm{~mm}$ long \\
\hline Vacuum valves & $\begin{array}{l}\text { Whitey "D" series, Whitey “40" series, Nupro "DL" series, Nupro } \\
\text { "LD" series; South Scotland Valve \& Fitting Co. Ltd. }\end{array}$ \\
\hline Gauges & $\begin{array}{l}\text { APG active Pirani gauge APM-M-NW } 25 \text { ST/ST (atmosphere to } \\
1 \mathrm{E}-4 \text { mbar) } \\
\text { WRG Active wide range gauge (atmosphere to } 1 \mathrm{E}-9 \text { mbar) } \\
\text { ASG Active strain gauges ( } 2000 \text { to } 1 \text { mbar) }\end{array}$ \\
\hline $\begin{array}{l}\text { Electronic control and } \\
\text { display units }\end{array}$ & AGC-TRIPLE DISP, RS232, 6 HEAD ADD active digital display \\
\hline Turbomolecular pump & $\begin{array}{l}\text { BOC Edwards, West Sussex; EXT compound molecular pump with } \\
\text { incorporated controller }\end{array}$ \\
\hline Scroll pump & BOC Edwards; West Sussex; XDS10C \\
\hline
\end{tabular}

